\title{
Práticas multidisciplinares para 0 ensino introdutório de Geociências
}

\author{
MultidisCIPLINARY PRACTICES FOR THE INTRODUCTORY TEACHING OF GEOSCIENCES \\ Matheus KuChenBeCKeR ${ }^{1}$ \\ 1- Laboratório de Estudos Tectônicos/CeGeo/ICt/UFVJM, Rod. MGT367, km583, nº 5000, Alto da Jacuba, 39100-000 Diamantina/MG e C. Pesq. Manoel Teleera \\ da Costa, Inst. Geoc., Univ. Fed. Minas Gerals, Av. Antônio Carlos 6627, Pampulha, 31270901 Belo Horizonte, MG. - mk.geologia@gmail.com
}

ABSTRACT: The aim of this paper is to present teaching practices which use applied geology subjects to introduce these areas of knowledge and also exercise basic geology. We want to show that this kind of approach has many pedagogical advantages, such as to valorize the students' previous knowledge and the development of a quasi-professional beneficial experience. Here we describe teaching practices which involve geophysics, hydrogeology and mineral prospecting, followed by all their didactic resources. In each case, we highlight the didactic potential of the proposed situations, as well as briefly describe the expected results.
Manuscrito:

Recebido: 30/ago/17

Corrigido: 29/out/17

Aceito: 02/dez/17

Citation:Kuchenbecker M. 2017. Práticas multidisciplinares para 0 ensino introdutório de Geociências. Terræ Didatica, 13(3):303-309. $<$ http://www.ige.unicamp.br/terraedidatica/>.

Keywords: applied geology, teaching practices, geology introductory courses, exercises.

\section{Introdução}

Nos cursos de Geologia ou Engenharia Geológica, as disciplinas de Introdução à Geologia (cujo nome varia bastante de universidade para universidade, passando por Geologia Geral, Fundamentos de Geologia, Sistema-Terra ou Geologia Introdutória) representam uma porta de entrada para as geociências, mas também atuam como cartão de visitas desta área do conhecimento. Se, por um lado, estas disciplinas cumprem o objetivo de estabelecer um alicerce sólido sobre o qual todo o curso se estabelecerá, por outro, elas têm como compromisso deslumbrar os estudantes, despertando neles ávido interesse pela Geologia. Este interesse é peça fundamental para que o aluno desenvolva, ao longo do curso, uma postura ativa no processo de aprendizado, buscando autonomamente ampliar seus horizontes científicos.

O ensino de Geologia Introdutória apresenta diversos desafios. O primeiro decorre da quase (ou total) ausência de temas relacionados à Geologia no ensino básico brasileiro, problema há muito conhecido e discutido. De acordo com os Parâmetros Curriculares Nacionais para o Ensino
Médio (PCNEM), conteúdos geocientíficos são propostos de forma disseminada em disciplinas como Física, Química, Biologia e Geografia. No entanto, segundo Toledo (2005), estes conteúdos têm tido um tratamento fragmentado e disperso, insuficiente para promover a compreensão do Sistema Terra em sua complexidade e dinâmica. Em decorrência disto, em geral, os estudantes ingressam nos cursos de Geologia ou Engenharia Geológica pouco familiarizados com os conteúdos geocientíficos, e menos conscientes ainda da atuação profissional do geólogo.

A intenção deste trabalho é apresentar alguns exemplos práticos de exercícios para utilização em disciplinas de Geologia Introdutória, tendo como temática principal a Geologia Aplicada. Ao longo do texto, são discutidas as vantagens deste tipo de abordagem, evidenciando-se as múltiplas habilidades e conhecimentos exercitados em cada exemplo. Os exercícios apresentados têm sido aplicados ao longo dos últimos três anos, com bons resultados, nas disciplinas introdutórias do curso de Engenharia Geológica da Universidade Federal dos Vales do Jequitinhonha e Mucuri, em Diamantina, Minas Gerais. 


\section{Exercícios práticos de Geologia Aplicada no âmbito das disciplinas de Introdução à Geologia}

Tendo em vista que as disciplinas de Introdução à Geologia devem oferecer um alicerce teórico para toda a estrutura curricular dos cursos de Geologia ou engenharia geológica, as abordagens envolvendo aplicações práticas dos conhecimentos geológicos podem ser extremamente efetivas do ponto de vista pedagógico. Temas como hidrogeologia, geofísica, exploração mineral e Geologia do petróleo, se abordados de maneira simples, objetiva e multidisciplinar, podem representar excelentes catalisadores para o interesse dos estudantes, tornando inclusive mais efetivo o aprendizado da Geologia como um todo.

Dentre as vantagens de se abordar temas de Geologia Aplicada, destacam-se: (i) os estudantes têm um primeiro contato com a importância, as aplicações e a terminologia específica destas áreas, criando uma base sólida que os auxiliará nas futuras disciplinas profissionalizantes; (ii) a resolução de problemas aplicados requer, necessariamente, habilidades e conhecimentos de Geologia Básica que são, desta forma, exercitados; (iii) os estudantes, ao serem instigados com problemas práticos cuja resolução demanda conhecimentos geológicos que eles já possuem, têm uma primeira experiência de natureza "profissional", o que desenvolve um sentimento benéfico de "pertencimento" à área.

Além disso, deve-se ressaltar a importância crucial das atividades práticas no processo de aprendizagem dos conteúdos geocientíficos. Se, por um lado, as atividades de campo constituem o principal meio pelo qual os geólogos efetivam sua prática (Carneiro et al. 1993), por outro, as atividades práticas realizadas em sala de aula também apresentam grande potencial pedagógico. Exercícios práticos, de acordo com Caamaño (2003), são atividades especialmente orientadas, projetadas para se aprender determinadas habilidades ou para ilustrar ou corroborar aspectos teóricos. As vantagens pedagógicas deste tipo de abordagem - incluindo seu caráter motivacional - têm sido amplamente discutidas, não só no âmbito da Geologia mas das ciências em geral (e.g. Bonito 2001, Bassoli 2014, Constante \& Vasconcelos 2010).

Abaixo são descritas práticas de ensino que têm como enfoque principal diferentes áreas da Geologia. É importante mencionar que as situações geológicas apresentadas são hipotéticas e extremamente simplificadas e visam potencializar o ensino de cada tema abordado. Ressalta-se ainda que estes são apenas exemplos, e que muitas outras práticas semelhantes podem ser desenvolvidas seguindo a mesma lógica. Por exigirem alguns conhecimentos prévios de Geologia Básica e desenho geológico, sugere-se que as práticas sejam apresentadas aos discentes no terço final das disciplinas, ou em disciplinas introdutórias complementares.

\section{Geofísica}

Em breve exposição, pode-se apresentar aos discentes os conceitos básicos da geofísica, ressaltando-se a sua importância em estudos teóricos (Geofísica Pura) e aplicados (Geofísica Aplicada). Um bom exemplo de Geofísica Pura, neste sentido, é o estudo do comportamento de ondas sísmicas para a obtenção de informações sobre a estrutura interna da Terra. Como exemplos de Geofísica Aplicada, por sua vez, pode-se mencionar o uso de métodos sísmicos na pesquisa de hidrocarbonetos, ou as aplicações de GPR em pesquisa hidrogeológica. Em seguida, pode-se apresentar de maneira simplificada os principais métodos geofísicos, com bons exemplos visuais de cada um. A título de sugestão, indica-se apresentar magnetometria, gravimetria, gamaespectometria, eletrorresistividade e sísmica, sempre fazendo alusão às disciplinas de física relacionadas a estes conteúdos, que os discentes já terão cursado ou irão cursar.

De crucial importância, em relação à geofísica, é transmitir a compreensão de que rochas diferentes possuem propriedades físicas distintas, que podem ser medidas, e enfatizar a importância destes dados indiretos em situações em que não se tem acesso direto às rochas.

\section{Descrição da prática}

O exercício proposto trata utiliza variações na intensidade magnética de diferentes rochas como auxílio ao mapeamento geológico e prospecção mineral. Na montagem do exercício, foi projetado um mapa geológico hipotético com camadas de quartzito e filito hematítico, basculadas para leste, cortadas por um dique vertical, de direção nordeste, de magnetita gabro (Fig. 1). É apresentado aos discentes, no entanto, apenas o mapa topográfico da área, onde está marcada uma malha regular de pontos de medição de intensidade magnética e 
alguns pontos de descrição em campo (Fig. 2).

Adicionalmente, são fornecidos: (i) a tabela de dados decorrentes deste levantamento, com valores hipotéticos de intensidade magnética dispostos segundo a seguinte lógica: gabro>filito>quartzito; (ii) as descrições sucintas dos afloramentos hipotéticos, onde são dadas informações estratégicas para o exercício, como a mineralogia e a atitude de planos de acamamento ou contatos.

Dois pontos de contato foram dispostos propositalmente sobre curvas de nível, para que os estudantes possam, a partir do método das horizontais, traçar com exatidão os contatos.

De posse destes dados, são requeridos dos estudantes o mapa geológico preliminar da região, bem como um perfil geológico e a caracterização de cada unidade do ponto de vista de espessura, atitude e intensidade magnética. Além disso, pede-se que seja descrita a história geológica da região.

\section{Potencialidades}

Ao realizarem este exercício, os estudantes estarão trabalhando os seguintes conteúdos e habilidades: (i) noções básicas de mineralogia e magnetometria, pois terão que associar as diferentes faixas de intensidades magnéticas ao conteúdo mineralógico de cada litotipo; (ii) noções básicas de lógica geológica, uma vez que terão que reconhecer o ordenamento de eventos (deposição, metamorfismo/deformação, intrusão, erosão) a partir do mapa; (iii) noções básicas de cartografia, como escala e curvas de nível; (iv) noções básicas de desenho geológico, ao traçar os contatos e o perfil geológico.

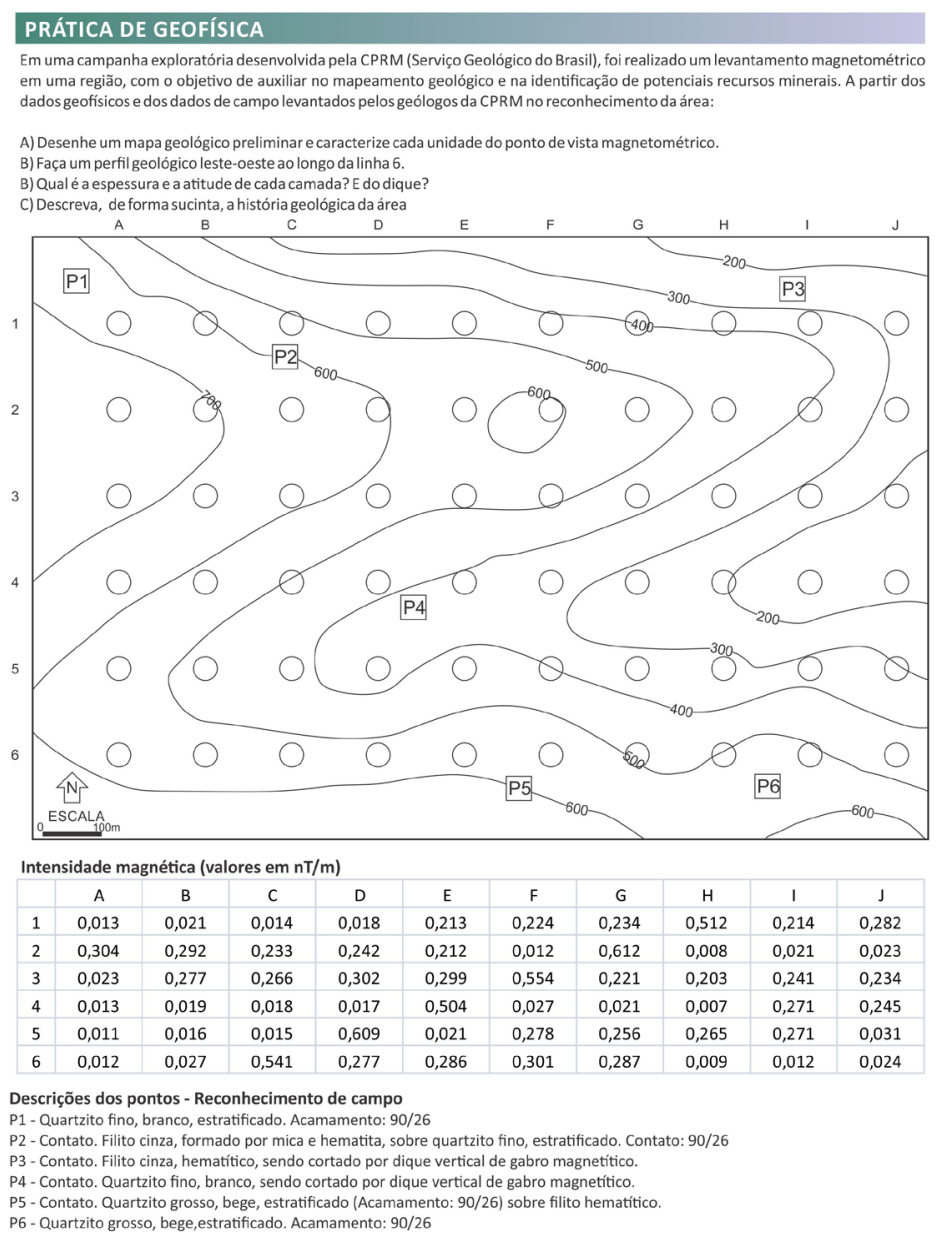

Figura 1. Prática de geofísica, incluindo o mapa, as questões e as informações necessárias para a resolução

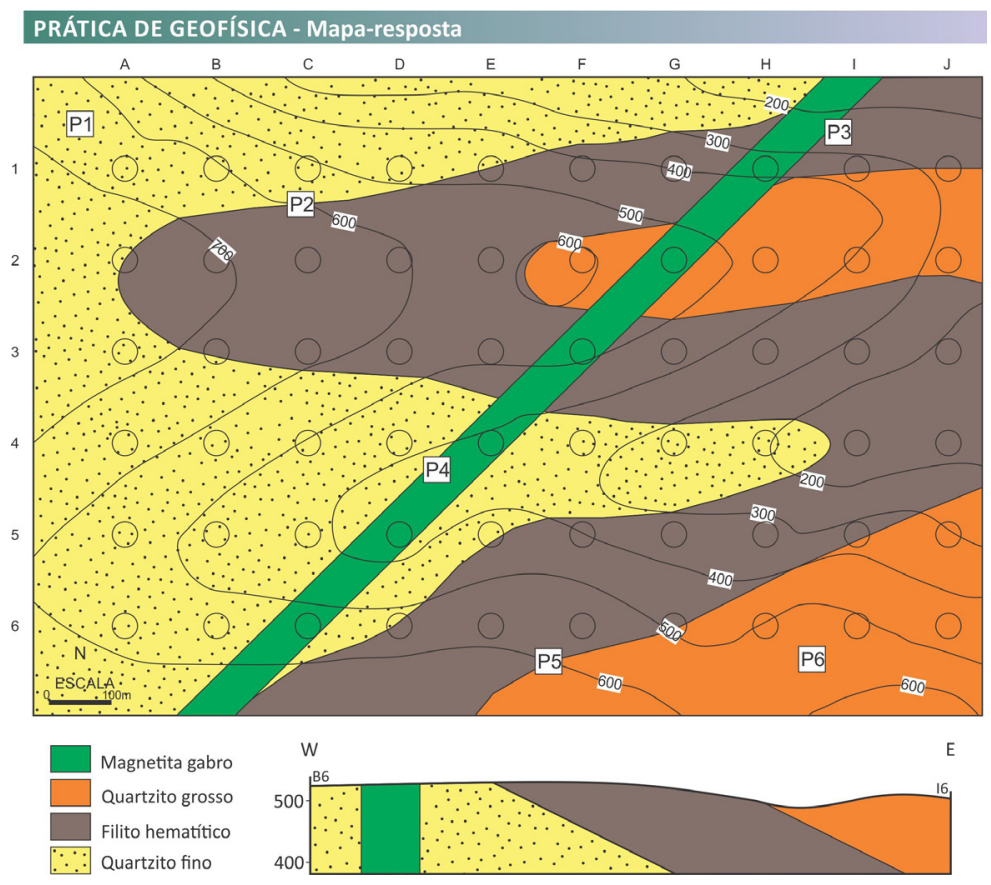

Figura 2. Mapa-resposta para a prática de geofísica, com perfil sintético ao longo de parte da linha 6 


\section{Resultados esperados}

Como os valores hipotéticos de intensidade magnética do gabro são substancialmente maiores que os demais e encontram-se alinhados em uma direção, espera-se que o dique seja a primeira feição reconhecida pelos discentes. Em dois dos pontos de campo fornecidos são descritos contatos do dique com as demais unidades, permitindo a estimativa de sua espessura.

Através da distribuição dos valores mais baixos e intermediários de intensidade magnética, espera-se que os discentes consigam estimar grosseiramente as zonas de afloramento de filito hematítico e quartzito. Em seguida, através do método das horizontais, os contatos deverão ser traçados com maior precisão, para então ser confeccionado o perfil geológico.

\section{Hidrogeologia}

$\mathrm{Na}$ abordagem geoquímica, em uma breve aula teórica pede-se os conceitos básicos da área, enfatizando-se suas aplicações em petrologia, mineralogia, geocronologia, paleoclimatologia, estratigrafia, prospecção mineral e outros. Em seguida, são apresentados os principais tipos de aquíferos existentes, tanto com base no tipo de porosidade (aqüíferos porosos, cársticos e fraturados) e no grau de liberdade (aqüíferos livres, confinados, suspensos), dando-se exemplos de rochas e situações geológicas pertinentes a cada caso

São essenciais, neste ponto, os conceitos de porosidade, permeabilidade, lençol freático, área de recarga e fluxo subterrâneo, em especial para que se crie o entendimento de que aqüíferos são unidades rochosas.

\section{Descrição da prática}

Na prática proposta, é apresentado aos alunos um mapa geológico simples, que exibe camadas de rochas sedimentares dobradas, sobre embasamento gnáissico. Com base no mapa e nos conhecimentos dos estudantes sobre os tipos rochosos apresentados, solicita-se: (i) a confecção de um perfil geológico e de um mapa hidrogeológico com os potenciais aquíferos; (ii) a locação de um poço para explotação de água, devidamente justificada; (iii) o cálculo da profundidade em que o poço locado atingiria uma camada específica; (iv) a locação de uma área para a instalação de um empreendimento potencialmente poluidor, devidamente justificada; (v) a descrição da história geológica da região.

Após a realização da prática pela turma, uma atividade interessante é pedir que cada aluno declare onde furaria o poço e faça a defesa dos argumentos que guiaram a sua locação.

\section{Potencialidades}

Na realização desta prática, os alunos estarão exercitando os seguintes conteúdos e habilidades: (i) noções básicas de hidrogeologia, pois terão que

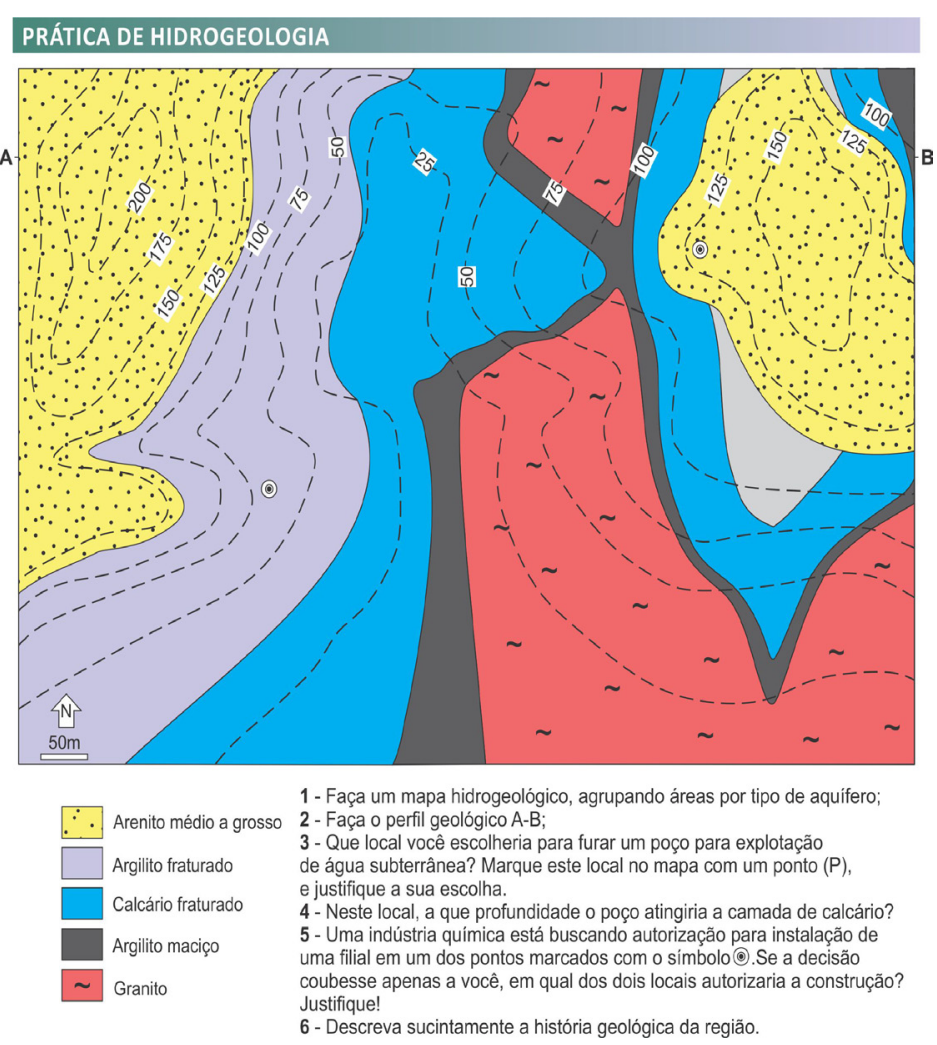

Figura 3. Prática de hidrogeologia proposta

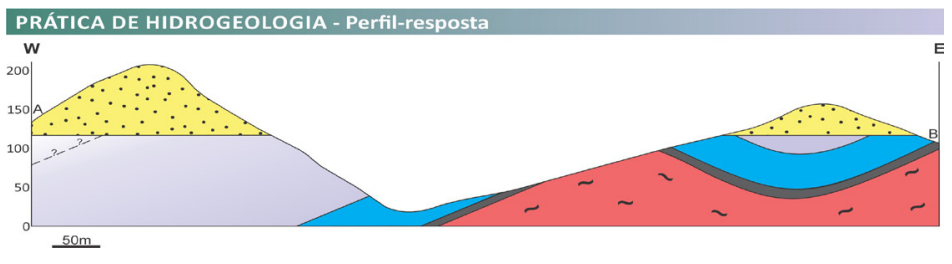

Figura 4. Perfil geológico AB, resposta parcial do exercício proposto 
associar cada litotipo a um perfil de permeabilidade e porosidade, bem como pensar em potenciais armadilhas para a água subterrânea, raciocinando sobre o fluxo da mesma; (ii) noções básicas de lógica geológica, uma vez que terão que reconhecer o ordenamento de eventos (deposição, deformação, erosão) a partir do mapa; (iii) noções básicas de cartografia, como escala e curvas de nível; (iv) noções básicas de desenho geológico, ao traçar o perfil geológico e executar o cálculo da profundidade; (v) noções importantes sobre geologia ambiental, ao raciocinar sobre poluição potencial de áreas de recarga.

\section{Resultados esperados}

$\mathrm{Na}$ confecção do mapa hidrogeológico, em geral, as primeiras unidades a ser demarcadas serão o arenito (aquífero poroso livre) e o calcário (aquífero cárstico-fraturado). Possivelmente haverá dúvidas quanto ao grau de liberdade do calcário (se livre ou confinado), a depender da área do mapa que se esteja analisando, o que pode render uma discussão interessante. É possível, também, que o gnaisse não seja considerado um aquífero potencial, e por isso é importante guiar os alunos a pensar nas fraturas.

$\mathrm{Na}$ locação dos poços muitas argumentações poroso. Neste ponto, é importante guiar a discussão pela importância na preservação das áreas de recarga, em especial mencionando dados sobre o grande tempo de residência da água nos aquíferos e suas conseqüências.

\section{Geoquímica e Prospecção Mineral}

Por seu caráter multidisciplinar, a prospecção mineral pode ser utilizada como tema para inúmeras práticas. Os exemplos que se seguem têm como tema a aplicação da geoquímica à prospecção mineral, e podem ser utilizados como exercício após uma breve exposição dos conceitos fundamentais da geoquímica, onde se enfatize suas múltiplas aplicações em geologia básica e aplicada. Um exemplo didático de geoquímica em Geologia Básica é sua utilização em estudos petrogenéticos ou paleoclimáticos. No campo da ciência aplicada, podem ser mencionadas as várias abordagens geoquímicas em Geologia econômica, da exploração à produção mineral.

Durante esta exposição teórica, o principal objetivo é transmitir aos discentes que diferentes rochas terão diferentes composições químicas, que podem ser medidas para a obtenção de informações sobre os processos que elas registram. É de fun- são possíveis, e por isso a realização da "defesa de locação" para toda a turma oferece a oportunidade de uma rica discussão. Deve ser estimulada a reflexão sobre o fluxo subterrâneo, sobre as potenciais armadilhas para a água e sobre a possível conexão entre aquíferos, bem como a sobre a possibilidade de se acessar mais de um aquífero no mesmo poço. Comumente virão à tona as seguintes situações: (i) poço no cume do morro oeste da área, para aproveitamento da maior espessura de arenito; (ii) poço no cume do morro leste da área, justificado pelo aproveitamento de múltiplos aquíferos, com rendimento potencializado pelo sinclinal, que funcionaria como armadilha para concentração da água no aquífero cárstico.

Quando da locação de um potencial agente poluidor, espera-se que os estudantes evitem o local situado sobre a área de recarga do aquífero

\section{PRÁTICA DE GEOQUÍMICA E PROSPECÇÃO MINERAL}

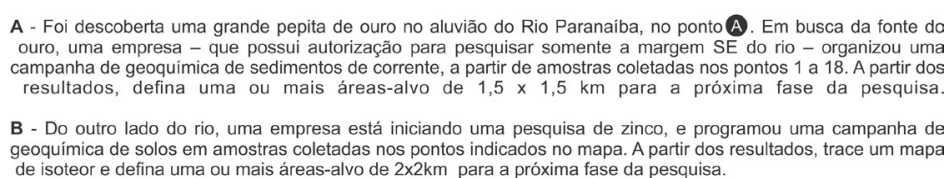
geoquímica de solos em amostras coletadas nos pontos indicados no mapa. A partir dos resultados, trace um mapa de isoteor e defina uma ou mais áreas-alvo de $2 \times 2 \mathrm{~km}$ para a próxima fase da pesquisa.

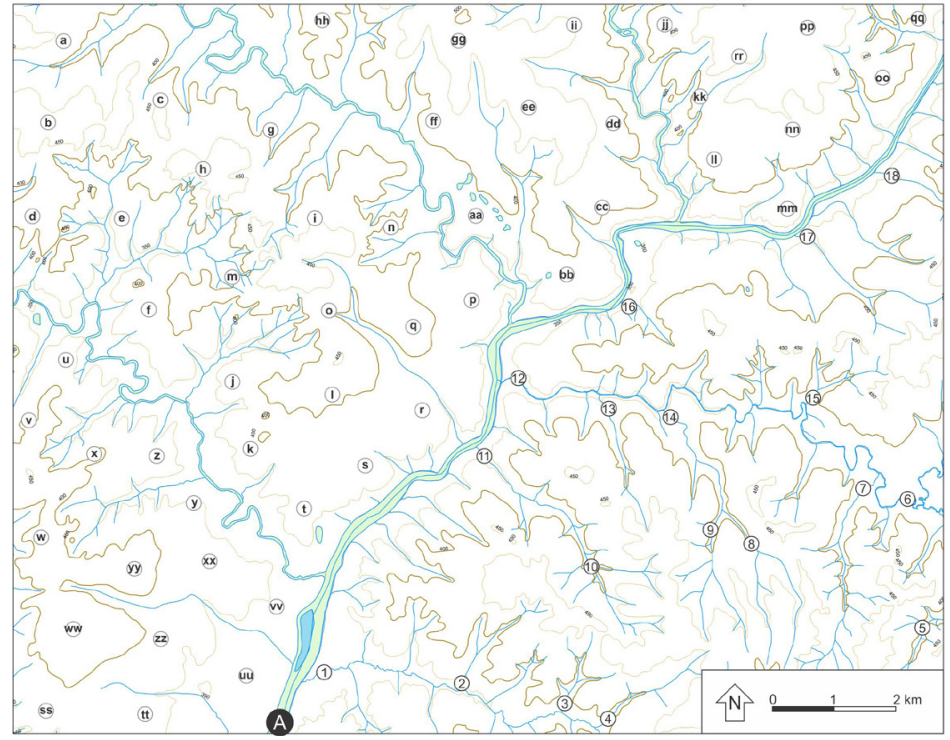

Figura 5. Prática de geoquímica aplicada à prospecção mineral 


\begin{tabular}{|c|c|} 
A Ponto & Au (ppb) \\
\hline 1 & 2,6 \\
\hline 2 & 0,11 \\
\hline 3 & 1,17 \\
\hline 4 & 4,41 \\
\hline 5 & 2,62 \\
\hline 6 & 1,65 \\
\hline 7 & 2,9 \\
\hline 8 & 3,12 \\
\hline 9 & 4,29 \\
\hline 10 & 3,7 \\
\hline 11 & 2,83 \\
\hline 12 & 2,11 \\
\hline 13 & 2,6 \\
\hline 14 & 2,92 \\
\hline 15 & 0,21 \\
\hline 16 & 0,45 \\
\hline 17 & 0,52 \\
\hline 18 & 0,65 \\
\hline
\end{tabular}

\begin{tabular}{|c|c|c|c|c|c|}
\hline Ponto & Zinco (ppm) & Ponto & Zinco (ppm) & Ponto & Zinco (ppm) \\
\hline$a$ & 132 & $s$ & 88 & kk & 123 \\
\hline b & 125 & $\mathrm{t}$ & 111 & $\|$ & 114 \\
\hline c & 131 & $\mathrm{u}$ & 122 & $\mathrm{~mm}$ & 107 \\
\hline d & 118 & $v$ & 142 & $\mathrm{nn}$ & 110 \\
\hline $\mathrm{e}$ & 122 & $x$ & 136 & 00 & 113 \\
\hline$f$ & 112 & $z$ & 123 & $\mathrm{pp}$ & 119 \\
\hline $\mathrm{g}$ & 142 & $y$ & 121 & qq & 115 \\
\hline$h$ & 133 & $w$ & 145 & $\mathrm{rr}$ & 125 \\
\hline$i$ & 135 & aa & 132 & ss & 148 \\
\hline $\mathrm{j}$ & 108 & $b b$ & 115 & $\mathrm{tt}$ & 145 \\
\hline k & 107 & cC & 126 & uu & 134 \\
\hline$I$ & 104 & $\mathrm{dd}$ & 135 & w & 122 \\
\hline$m$ & 124 & ee & 149 & $x x$ & 127 \\
\hline$n$ & 131 & $\mathrm{ff}$ & 147 & $\mathrm{zz}$ & 147 \\
\hline 0 & 123 & gg & 179 & yy & 142 \\
\hline$p$ & 121 & $\mathrm{hh}$ & 145 & $w w$ & 163 \\
\hline q & 120 & $\mathrm{ii}$ & 144 & & \\
\hline$r$ & 106 & $\mathrm{jj}$ & 133 & & \\
\hline
\end{tabular}

te do rio, é enunciado um problema envolvendo campanha de prospecção de ouro, baseada em geoquímica de sedimentos de corrente, amostrados em pontos específicos marcados no mapa. Já na área a noroeste é apresentado um problema relacionado a campanha para prospecção de zinco, baseada em geoquímica de

Figura 6. Resultados de análises químicas de sedimentos de corrente e solos, para utilização solo, amostrado em na prática de geoquímica aplicada à prospecção mineral

pontos marcados no

damental importância destacar a diferença entre a geoquímica elementar e a geoquímica isotópica, apresentando exemplos práticos para cada caso.

\section{Descrição da prática}

Na prática de geoquímica aplicada à prospecção mineral apresenta-se um mapa topográfico atravessado diagonalmente por um grande rio, às margens do qual se desenvolvem duas atividades prospectivas hipotéticas (Fig. 5). Na área a sudes-

\section{PRÁTICA DE GEOQUÍMICA E PROSPECÇÃO MINERAL - Mapa-resposta}

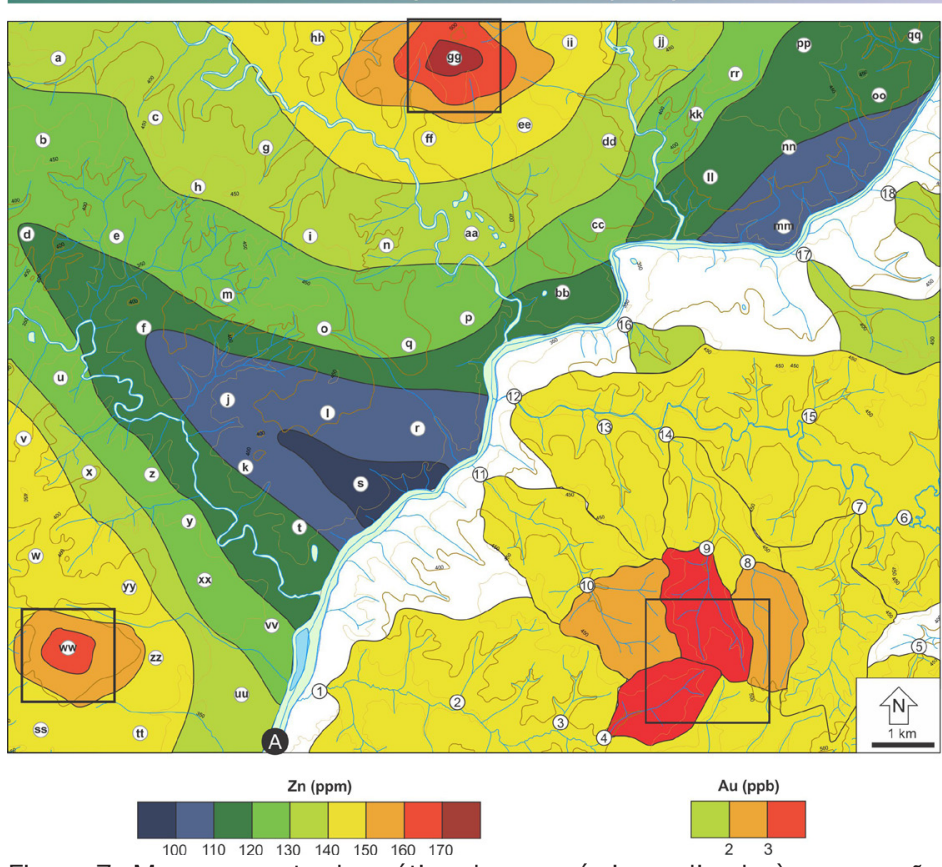

Figura 7. Mapa-resposta da prática de geoquímica aplicada à prospecção mineral. Os quadrados pretos indicam a melhor localização dos alvos solicitados nas questões mapa. Os dados relacionados aos dois problemas são apresentados em tabelas separadas (Fig. 6).

No primeiro problema, requer-se que os alunos analisem os dados e delimitem um alvo para a próxima campanha na área mais promissora encontrada. No segundo problema, solicita-se a confecção de um mapa de isoteores a partir dos dados fornecidos, com a delimitação de um ou mais alvos promissores.

\section{Potencialidades}

Na realização desta prática, os alunos estarão exercitando os seguintes conteúdos e habilidades: (i) noções básicas de cartografia e hidrografia, pois terão que associar os resultados geoquímicos de sedimentos de corrente às bacias hidrográficas correspondentes, delimitando-as; (ii) noções básicas de geoestatística, pois terão que interpolar os resultados de geoquímica de solo para a geração de um mapa simples de isoteores; (iv) noções básicas de prospecção mineral, ao lidar com a delimitação de alvos e pensar diferentes fases da pesquisa mineral.

\section{Resultados esperados}

$\mathrm{Na}$ questão A, espera-se que os alunos rapidamente identifiquem os pontos com teores mais altos, e comecem a delimitar as bacias hidrográficas 
a partir destes. Após a delimitação dos principais pontos de amostragem a área fonte do ouro ficará em evidência, tornando fácil a delimitação do alvo (Fig. 7). Durante a realização desta questão é importante levar os estudantes a refletir sobre o significado da amostragem de sedimentos de corrente, para que compreendam que os resultados de cada ponto fornecem informações sobre toda a bacia sedimentar a montante dali.

Na questão B, por sua vez, é importante compreender que o resultado de cada análise diz respeito exclusivamente ao ponto amostrado. Espera-se que os estudantes rapidamente identifiquem os pontos com mais altos teores, e deve-se orientá-los a iniciar a interpolação a partir destes pontos, desenhando curvas de isoteor a cada $10 \mathrm{ppm}$. Durante a prática, uma discussão sobre os métodos de interpolação possíveis e suas diferenças é importante, ainda que para a realização do exercício uma interpolação aproximada seja o suficiente.

\section{Conclusões}

Este trabalho pretende estimular a utilização de problemas baseados em situações geológicas reais na construção de práticas para o ensino introdutório de Geologia, além de oferecer à comunidade docente algumas práticas já testadas. Espera-se que o trabalho incentive outros colegas a socializar suas práticas de ensino, de modo a contribuir para o fortalecimento do ensino de Geologia no Brasil.

Do exposto, conclui-se que temas relacionados às áreas aplicadas da Geologia permitem a construção de inúmeras práticas de ensino multidisciplinares, que podem ser aplicadas com sucesso em disciplinas de Introdução à Geologia. Tal abordagem é extremamente benéfica ao aprendizado, uma vez que: (i) proporciona um primeiro contato com as aplicações e os termos de novas áreas do conhecimento, preparando os discentes para futuras disciplinas; (ii) valoriza e exercita os conhecimentos geológicos prévios dos discentes; (iii) instiga os discentes com problemas reais, oferecendo uma experiência "profissional" que desenvolve sentimento benéfico de "pertencimento" à área.

\section{Agradecimentos}

Agradecimentos são devidos aos alunos dos últimos cinco semestres das disciplinas Sistema-Terra I e Sistema Terra II do curso de Engenharia Geológica da UFVJM que, por meio da utilização prática, ajudaram a aprimorar as práticas de ensino aqui apresentadas.

\section{Referências}

Bonito J. 2001. As atividades práticas no ensino das Geociências. Um estudo que procura a conceptualização. Lisboa: Inst. Inov. Educ.

Bassoli F. 2014. Atividades práticas e o ensino-aprendizagem de ciência(s): mitos, tendências e distorções. Ciênc. E Educ. 20(3):579-593.

Caamaño A. 2003. Los trabajos prácticos en Ciencias. In: Caamaño A., Oñorbe A., Pedrinaci E., Pro A., Aleixandre M. P. eds. Enseñar ciências. Barcelona: Graó. p. 95-118.

Carneiro C.D.R., Cunha C.A.L.S., Campanha G.A.C. 1993. A teoria e a prática em Geologia e o eterno retorno. Rev. Bras. Geoc., 23(4):339-346.

Constante A. Vasconcelos C. 2010. Actividades lúdico-práticas no ensino da Geologia: complemento motivacional para a aprendizagem. Terre Didatica, 6(2), 101-123.

Toledo M.C.M. 2005. Geociências no Ensino Médio Brasileiro - Análise dos Parâmetros Curriculares Nacionais. Geol. USP, Publ. Espec. 3:31-44.

Resumo: 0 objetivo deste trabalho é apresentar práticas de ensino que utilizam temas de Geologia Aplicada para introduzir estas áreas do conhecimento e, ao mesmo tempo, exercitar habilidades de Geologia Básica. Pretende-se demonstrar que este tipo de abordagem apresenta diversas pedagogias, dentre elas a valorização dos conhecimentos prévios dos alunos e 0 oferecimento de uma benéfica experiência quase-profissional. São aqui descritas práticas relacionadas a geofísica, hidrogeologia e prospecção mineral, acompanhadas de todo o material necessário para sua utilização em sala de aula. Em cada caso, são evidenciadas as potencialidades didáticas das situações apresentadas, bem como um sumário dos resultados esperados.

Palavras-chave: Geologia Aplicada, práticas de ensino, Geologia Introdutória, exercícios. 